\title{
HOSPITAL DE CUSTÓDIA E TRATAMENTO PSIQUIÁTRICO NO BRASIL: UMA ANÁLISE SOBRE SEUS FUNDAMENTOS E PERMANÊNCIA
}

\section{Gabriela Silva Paixão ${ }^{1}$}

\section{Resumo:}

O Hospital de Custódia e Tratamento Psiquiátrico, um híbrido de hospício e prisão, permanece no Brasil, em oposição à desinstitucionalização promovida pela Reforma Psiquiátrica. Diante dessa contradição, analisar-se-á os fundamentos teórico-normativos de sua existência; a conjugação do interesse científico do Direito Penal e da Psiquiatria em patologizar o crime; e sua permanência baseada apenas na noção de periculosidade presumida do louco-infrator. Busca-se, também, compreender como a medida de segurança atua enquanto instrumento de contenção do crime-louco. Para tanto, realizou-se pesquisa teórica sobre o tema, por meio de acesso à bibliografia especializada e da coleta de dados legislativos e jurisprudenciais.

\section{Palavras-chave:}

Hospital de Custódia e Tratamento Psiquiátrico. Louco-infrator. Permanência. Medida de Segurança. Reforma Psiquiátrica

\section{FORENSIC MENTAL HEALTH SETTINGS IN BRAZIL: A STUDY ON ITS PRINCIPLES AND ENDURENCE}

\begin{abstract}
:
A forensic mental health setting, an institution that is a hybrid of prison and asylum, persistis in Brazil, despite of the Psychiatric Reform and its deinstitutionalisation. Because of its contradiction, this paper analyzes the theoretical and normative substance this social space; the agreement between Criminal Justice and Psychiatry to pathologize the crime; and its endurence only based in the notion of presumptuous dangerousness of the criminal lunatic. This paper also intends to clarify the role of the security measure in the criminal lunatics control. This is a theoretical research into specialized bibliography and a collect of legislative and decisional data.
\end{abstract}

Keywords:

Forensic Mental Health Setting. Criminal Lunatic. Endurance. Security Measure. Psychiatric Reform

\section{INTRODUÇÃO}

\footnotetext{
${ }^{1}$ Mestranda no Programa de Pós-Graduação em Direito da UFS. Especialização em Filosofia e Teoria do Direito pela PUC-MG. Graduada em Direito pela UFS. Analista - Área Jurídica do Ministério Público do Estado de Alagoas. Endereço postal: Praça Luciano Barreto Júnior, 56, apto 301, Jardins, Aracaju/SE, CEP 49025-335. Endereço eletrônico: gabi.spaixao1994@gmail.com
} 
A obra Crime e Loucura: o aparecimento do Manicômio Judiciário na passagem do século, do antropólogo brasileiro Sérgio Carrara, é originada de um trabalho de campo no antigo Manicômio Judiciário (MJ) Heitor Carrilho, no Rio de Janeiro da década de 80. Sua leitura despertou a curiosidade sobre o panorama teórico que permitiu o surgimento desse tipo de instituição no Brasil, e provocou, ao mesmo tempo, um profundo desconforto em relação à sua permanência. Não há como evitar que se faça um contraponto entre a Psiquiatria democrática do fim do século XX, aliada à luta antimanicomial, e a existência, ainda no século XXI, de um espaço de segregação psiquiátrico-penal. Esboça-se, então, o objetivo deste trabalho: analisar seus fundamentos teóricos e a sua permanência.

Consoante a legislação penal brasileira, o indivíduo portador de doença mental que cometer fato tipificado como crime e que, ao tempo, era inteiramente incapaz de entender o caráter ilícito do fato, ou de determinar-se de acordo, é inimputável e pode ser internado em Hospital de Custódia e Tratamento Psiquiátrico (HCTP). Mas o que seria esse local?

Como o próprio nome já antecipa, essa é uma instituição que agrega mecanismos de natureza penal e psiquiátrica, o que a torna um híbrido de hospício e prisão. Tal estruturação é decorrência direta do fato de que ela surgiu, no fim do século XIX, para abrigar aqueles que, na visão dos saberes jurídico e médico da época, possuíam a marca simultânea da insanidade mental e do perigo.

A problemática reside no fato de que, atualmente, a Psiquiatria entende e lida de forma distinta do Direito Penal em relação ao transtorno mental e ao seu portador. O tratamento segregativo, nos moldes manicomiais, perdeu credibilidade científica. Diante disso, conclui-se que o HCTP é um local totalmente inadequado para a promoção de um efetivo tratamento psiquiátrico, e seu único objetivo apenas pode ser o da contenção. É que o louco-infrator encontra-se numa zona nebulosa entre a política sanitária e a criminal.

Para a elaboração deste artigo realizou-se pesquisa teórica sobre o tema, tendo sido acessada bibliografia específica, bem como coletados dados legislativos e jurisprudenciais.

Dividir-se-á o desenvolvimento em três capítulos. O primeiro abordará o panorama teórico de surgimento da Psiquiatria e de sua interlocução com o Direito Penal para a criação do HCTP, único local autorizado a conter o indivíduo tido por louco-criminoso. Do mesmo modo, analisará como, nos dias atuais e após a superação de certos fundamentos, essa instituição ainda permanece, baseada apenas na noção de periculosidade presumida.

O segundo capítulo tratará, inicialmente, da teoria tripartida do delito e de seus 
conceitos correlatos de culpabilidade, inimputabilidade e irresponsabilidade. Após, analisará as normas penais que disciplinam a internação do inimputável por doença mental no HCTP, tendo por instrumento a medida de segurança do tipo detentiva.

O terceiro capítulo debruçar-se-á sobre o panorama teórico da Reforma Psiquiátrica no mundo, bem como sobre as mudanças implementadas nos setores de saúde mental a partir dela. Analisará, também, as possíveis influências desse fenômeno, consolidado no Brasil com a Lei de n. 10.216/2001, no sistema de custódia psiquiátrico-penal, especialmente no HCTP.

\section{O SURGIMENTO DO MANICÔMIO JUDICIÁRIO NO BRASIL: A PSIQUIATRIA, O DIREITO PENAL E O LOUCO-INFRATOR NA CONSTRUÇÃO E PERMANÊNCIA DA PERICULOSIDADE}

"Desde a primeira visita que fiz ao MJ, tive a impressão (dessas tão caras à antropologia) de estar entrando em uma instituição híbrida e contraditória [...] De certo modo, denunciava-se a prisão que existiria atrás de cada hospital” (CARRARA, 1998, p. 27). Este excerto define muito bem a sensação de estranheza que o HCTP desperta em um observador contemporâneo. É preciso, então, desvendar a sua história.

A Psiquiatria, que na concepção de Foucault (2013, p. 18) é exemplo de saber-poder produtor de seu próprio sujeito de conhecimento, surge, em fins do século XVIII, nas mãos do médico francês Philippe Pinel e seu gesto emblemático (talvez mítico) de rompimento das algemas dos internos dos hospitais de Bicêtre e de Salpêtrière (HARRIS,1993, p. 16).

Em meio ao denominado de grande internamento, onde se amontoavam, nas Casas de Correção/Hospitais Gerais, doentes, mendigos, vagabundos, prostitutas, e todos os demais indesejados socialmente, Pinel transporta aqueles tidos como alienados para uma outra segregação, agora científica, e transforma-os em objeto de conhecimento da medicina psiquiátrica nascente.

Ocorre que, nesse internamento, destacavam-se indivíduos que não eram dóceis à disciplina da instituição. Eram alheios à sua rotina, às suas relações interpessoais, aos seus dogmas sexuais, enfim, à sua essência (JACOBINA, 2008, p. 44). Tidos por alienados, eram acorrentados em espaços separados e passavam a vivenciar uma segregação em duplo grau, por assim dizer. A Psiquiatria, portanto, cria um novo ambiente para tratamento dessesindivíduos, mantendo as bases morais que justificavam seu internamento, mas acrescentando o rigor científico trazido pela noção de doença mental.

Surge o Manicômio, a partir dessa nova relação de poder ditada pela Medicina, 
caracterizada pelo "direito da não-loucura sobre a loucura, em que a primeira teria a incumbência de corrigir os erros de normalidade (ilusões, alucinações, fantasmas). E o sujeito que sofria desta doença era desqualifcado como louco" (WEIGERT, 2017, p. 51).

Até esse momento a loucura parecia ser uma categoria médica muito clara e pragmática: ou se é louco, ou não se é; ou há razão, ou não há. Ocorre que Pinel, ao classificaros níveis de loucura, cunhou o termo mania sem delírio, o qual correspondia a uma confusão mental distinta da ausência completa de razão, pois "certos pacientes pareciam raciocinar bem, exceto acerca de determinados assuntos e, interrogados nestas áreas, demonstravam incoerência ou extrema excitação" (HARRIS, 1993, p. 16).

Essa categoria oscilante entre razão e loucura permaneceu como objeto da Psiquiatria do século XIX. Foucault (2010, p. 134) discorre que foi a partir desse momento que surgiu o termo monomania, representando essa "loucura parcial, essa espécie de loucura que só atingiria como que um setor da personalidade [...] que não tocaria mais que um pequeno elemento do comportamento daquele indivíduo", e que, em um momento particular, agiu de maneira inexplicável pelos ditames da razão difundida. E é especialmente com as monomanias do tipo homicida e suicida que a essa doença mental será acrescido o atributo, ainda nascente, da periculosidade, pois tal conceito reforçava a função para a qual a Psiquiatria tinha surgido no fim do século XVIII: a de higienização pública (FOUCAULT, 2010, p. 100-102).

A conclusão acima é um ponto importante no desenvolvimento das relações entre Psiquiatria e Direito Penal. Ora, a noção de monomania, enquanto delírio parcial e imprevisível de indivíduos estigmatizados por um defeito em sua constituição orgânica, explicava de maneira bastante satisfatória os casos de crimes brutais cometidos por pessoas aparentemente saudáveis e com um histórico moral intacto. Ademais, para a sociedade, alguns crimes subvertiam os mais preciosos valores humanos de tal forma que apenas uma explicação médica do comportamento de parricidas e infanticidas, por exemplo, poderia ser aceita.

Assim, para crimes perpetrados por indivíduos monomaníacos que fim poderia ser definido para seus autores? Não se enquadravam no tratamento médico clássico da loucura. A prisão não era opção porque, de acordo com o sistema penal liberal, eram irresponsáveis. Delinear-se-á, como dito, a noção de periculosidade e, com ela, a de defesa social, as quais fundamentarão o surgimento do Manicômio Judiciário (MJ).

Contudo, a influência decisiva veio de duas outras categorizações médico-jurídicas, construídas nos anos que se seguiram: a da degeneração, difundida na França por Bénédict 
Morel, e a do criminoso nato, defendida por Cesare Lombroso, na Itália.

A degeneração seria o desvio em determinado estágio da evolução do indivíduo, uma disfunção orgânica que corresponderia à apropriação da teoria dos caracteres adquiridos, desenvolvida pelo biólogo francês Lamarck, na conceituação de determinadas doenças mentais (JACOBINA, 2008, p. 56-57). Diferentemente da época da monomania em que se focava no patológico, na teoria da degeneração a Psiquiatria, ampliando sobremaneira seu poder de ingerência na sociedade, voltará seus olhos aos comportamentos, condutas e estados dos indivíduos para explicar a origem da degeneração/anomalia, a qual será a loucura em si (FOUCAULT, 2010, p. 276).

Assim, ocorre uma transferência de objeto psiquiátrico, do monômano para o degenerado. Para Carrara (1998, p. 81), a partir dessa nova categorização do crime enquanto manifestação patológica, é que há, na segunda metade do século XIX, uma ruptura entre o binômio hospício/prisão, uma vez que o fundamento da punição encontra obstáculo na própria medicalização do crime.

O papel de embate direto e definitivo com o Direito Penal caberia à antropologia criminal. Cesare Lombroso, em fins do século XIX, busca aplicar a ideia de degeneração reformulada no atavismo - como política criminal da época. Consistia, precipuamente, na introdução do conceito de criminoso nato como sendo um indivíduo com características primitivas de um ancestral humano, em que a exasperação de seus impulsos e desejos selvagens culminariam, invariavelmente, na prática de crimes e na desordem social (HARRIS, 1993, p. 9394).

Diferente da teoria da degeneração, a qual tinha a loucura criminosa como um estágio de decadência da humanidade a que todos estávamos condenados, a teoria do criminoso nato, para Jacobina (2008, p. 84), enxergava o deliquente como fruto de um desvio na evolução darwiniana, reservado a certos indivíduos. A partir dela, a ideia de eliminação desses seres desviantes ganhou força, justificada na regra de sobrevivência do mais forte.

O mérito, se assim pode ser dito, da teoria do criminoso nato está no fato de que ela transpõe a Medicina, especificamente a Psiquiatria, e afeta toda a estruturação do Direito Penal, uma vez que colide frontalmente com o direito de punir clássico. Com isso, a responsabilização penal fundada no livre-arbítrio jamais poderia alcançar o criminoso nato, já que suas ações seguem imperativos de sua própria natureza degenerada. Não haveria vontade. Os monomaníacos, os degenerados, os criminosos natos, ou apenas os loucos- criminosos. 
Que destino dar a esses indivíduos? A medicina psiquiátrica já tinha formadoconclusões sobre eles que impossibilitavam o seu enquadramento no tratamento médico dos hospitais psiquiátricos tradicionais. O sistema penal preservava a autonomia da vontade (livre-arbítrio) como pressuposto da responsabilização criminal e, portanto, não era possível condená-los. A única certeza que persistia é que eram indesejados.

A apropriação médica da loucura pela Psiquiatria com a criação do Manicômio enquanto espaço autorizado para seu tratamento/cura chega ao Brasil em meados do século XIX, a partir da fundação do Hospício Dom Pedro II, no ano de 1852, e a inserção daquela cátedra nas principais Faculdades de Medicina do país (CORREIA, 2007, p. 28).

Antes, os loucos eram confiados aos hospitais e casas de misericórdia, que consistiam em "espaços de acolhimento piedoso, onde os religiosos recebiam excluídos, doentes, loucos, miseráveis e desgraçados" (JACOBINA, 2008, p. 62).

A Psiquiatria no Brasil segue, de certa forma, o percurso europeu no tocante à paulatina apropriação da explicação médico-científica de comportamentos tidos por desviantes. O diálogo travado entre Psiquiatria e Direito Penal, referente à destinação institucional do loucocriminoso, ocorre quase que simultaneamente nesses territórios. E o resultado dessa interlocução fez surgir, em solo europeu, a instituição do Manicômio Judiciário ainda no século XIX.

Havia, naquela época, a tendência em separar, dentro dos hospitais psiquiátricos, os loucos comuns dos loucos perigosos. Estes últimos eram exemplos de indivíduos monomaníacos ou degenerados, conforme a teoria da época, e, na maior parte das vezes, estavam envolvidos com práticas criminosas. Em nome da ordem, havia uma contenção dupla para esses indivíduos, segregados em alas ou seções específicas.

Outra dupla contenção ocorria nas prisões da época, onde os sentenciados que desenvolviam algum distúrbio mental superveniente à sua condenação eram recolhidos em alas separadas dos demais prisioneiros, sob o argumento de se evitar o abalo da ordem carcerária.

Um cenário propício, portanto, para pensar a criação de um espaço autônomo e simultâneo de contenção e tratamento de todos esses indivíduos: o futuro MJ. Como alguns criminosos recebiam o estereótipo da anomalia, seja ela de ordem biológica ou psíquica (ou ambas), eles não poderiam usufruir do benefício da cura estendido aos loucos comuns. Por outro lado, sua existência era um grande problema para a sociedade na qual estavam inseridos (já haviam demonstrado isso nos delitos) e, portanto, algo deveria ser feito. 
No Brasil, foi inaugurado, em 30 de maio de 1921, o primeiro MJ, na cidade do Rio de Janeiro, o qual tornou-se modelo para a construção de outros no restante do país, ao longo de todo o século XX. Uma instituição que permanece até hoje.

Fundado na noção de periculosidade presumida dos loucos-criminosos, essa construção médico-jurídica é o único sustentáculo do MJ na atualidade, posto que as teorias da alienação moral, da degeneração e do atavismo parecem ter sido superadas. A partir de um juízo probabilístico de condutas negativas, interna-se o sujeito em nome da paz social.

Ocorre que, hoje em dia, a explicação da origem de comportamentos desviantes não mais perpassa por características biodeterministas, como as que fizeram surgir o MJ. A monomania, a degeneração e o atavismo, apesar de ter seus fiéis seguidores, não mais se sustentam. E, por isso, a instituição atualmente abriga qualquer portador de transtorno mental o mesmo que antes era recolhido aos Manicômios comuns - autor de um delito.

Daí pode ser extraída a conclusão de que, dos dois fundamentos que criaram o MJ biodeterminismo criminológico e periculosidade - apenas o último sustenta a existência desse espaço. A construção da periculosidade do louco confunde-se com o próprio nascimento da Psiquiatria, quando ela identifica a loucura como doença e determina que o tratamento deve ser dado a partir da segregação do indivíduo em espaços médicos especializados (CORREIA, 2007, p. 45).

Já à época das teorias da degeneração, com sua identificação entre crime e doença, a periculosidade aparece como justificativa para a intervenção psiquiátrica em tipos criminosos. Nesse período, há um cruzamento de percurso entre o Direito Penal e a Psiquiatria e, consequentemente, a periculosidade também passa a ser um conceito jurídico, já que era preciso fundamentar legalmente a contenção do louco-criminoso.

É com o Código Penal de 1940 que a periculosidade é absorvida em definitivo pelo sistema jurídico, como fundamento para a custódia dos loucos-infratores. Seu art. 22 previa que seria inimputável o agente portador de doença mental que, ao tempo do delito, era incapaz de compreender o caráter ilícito de sua conduta ou de portar-se de outro modo. Constada a irresponsabilidade, a intervenção jurídica era justificada pela presunção de periculosidade desse agente, a qual encontrava guarida em seu art. 78, inciso I. Essa presunção de periculosidade é o que sustenta a intervenção jurídica no louco- criminoso, uma vez que, por aferição lógica, qualquer cidadão, seja ele doente mental ou não, tem "a potência, a capacidade e a aptidão ou idoneidade para converter-se em causa de ações danosas" (JACOBINA, 2008, p. 131), mas 
apenas ao inimputável por doença mental ela é aplicada.

Esse entendimento permanecerá mesmo após a Reforma Penal de 1984, como justificativa para a aplicação da medida de segurança detentiva e a consequente internação no HCTP, conforme infere-se da leitura do art. 97, $\S 1^{\circ}$, do CP.

O referido artigo também prevê que a desinternação dependerá de laudo médico de cessação de periculosidade. Logicamente, conclui-se que o internamento só ocorreu porque entendia-se que o doente mental era, aprioristicamente, perigoso.

Interessante observar, num primeiro momento, como a construção da personalidade perigosa do louco-infrator está apartada de um juízo médico. Até a determinação judicial da aplicação da medida de segurança, a perícia psiquiátrica limitar-se-á à verificação da inimputabilidade, sem qualquer perquirição quanto ao perigo anunciado por aquele indivíduo. Será apenas após a internação no HCTP que a periculosidade será objeto médico. Do exposto, infere-se que a presunção legal de periculosidade é a base da existência de um espaço como o HCTP.

Ressalte-se, contudo, que a medicina psiquiátrica vem rejeitando essa histórica concepção do portador de transtorno mental como um indivíduo perigoso, e, consequentemente, rejeita a sua apartação social para tratamento. Exemplo disso é o movimento da Reforma Psiquiátrica. O problema permanece, portanto, na inadequação do sistema jurídico ao sofrimento mental. Parece que o Direito Penal enxerga o louco-infrator com os mesmos olhos dos médicos da teoria da degeneração: um problemático irrecuperável. Uma visão atrasada em séculos.

Goffman (2015, p. 142), quando tratou de instituição total, afirmou que aquilo que conhecemos por $e u$ nada mais é aquilo que "o sistema social estabelece para seus participantes [...] não é uma propriedade da pessoa a que é atribuído, mas reside no padrão de controle social que é exercido pela pessoa e por aqueles que a cercam". Com isso, a periculosidade do portador de transtorno mental, tenha ele cometido crime ou não, é um atributo construído, que não condiz, necessariamente, com a sua realidade.

Caso essa constatação seja acatada, a existência do HCTP perde total fundamento.

\section{A NORMATIVA CONTEMPORÂNEA DO HOSPITAL DE CUSTÓDIA E TRATAMENTO PSIQUIÁTRICO: INIMPUTABILIDADE E MEDIDA DE SEGURANÇA}

Esclarecido o histórico e a fundamentação teórica do HCTP no Brasil, cumpre, agora, 
delinear sua normativa penal contemporânea.

Antes de analisar especificamente o instituto da medida de segurança e a legislação que a regulamenta, é importante falar sobre certos conceitos jurídicos que lhe dão origem: a culpabilidade, a inimputabilidade e a irresponsabilidade penal. É a partir dessas construções dogmáticas, extraídas da moderna teoria do crime, que se justifica a impossibilidade de aplicação de pena ao louco-criminoso e elege-se a medida de segurança como consequência penal.

O conceito analítico de crime corresponde a uma ação típica, antijurídica e culpável. Cada categoria é independente e sucessiva (BITENCOURT, 2016, p. 279). A questão da inimputabilidade do louco-criminoso está inserida na esfera da culpabilidade, enquanto hipótese de exclusão.

Da estrutura tripartida do delito, aquela é a categoria que possibilita a efetiva atribuição de responsabilidade penal a um indivíduo, após considerar suas características pessoais, impedindo, com isso, uma responsabilização objetiva (BITENCOURT, 2016, p. 439).

Neste panorama, ressalte-se que uma das principais contribuições para a teoria analítica do crime foi o finalismo wezeliano, adotado pelo Código Penal brasileiro, que, ao retirar os aspectos subjetivos da culpabilidade - dolo e culpa - e transferi-los para a tipicidade, estruturou-a a partir de elementos eminentemente objetivos, dando origem ao que se chama de teoria normativa pura.

É dentro desses elementos normativos, especificamente na imputabilidade, que se encontra a justificação da não aplicação de pena ao louco-criminoso e sua substituição pelo instituto da medida de segurança. Assim, são eles: a imputabilidade (capacidade de culpabilidade), potencial conhecimento da ilicitude do fato e exigibilidade de obediência ao direito (BITENCOURT, 2016, p. 457). Quando estão presentes no caso concreto, o último degrau de definição do crime é atingido e o Estado está apto a impor uma pena ao agente. Para o louco-criminoso é a imputabilidade, ou melhor a ausência dela, que exclui sua culpabilidade e justifica a imposição de medida de segurança.

Como já explanado, o Código Penal conceitua os elementos da culpabilidade em sua forma negativa, ou seja, apenas trata de suas excludentes. No caso da imputabilidade, pode-se inferir que ela é o contrário daquilo que preconiza o art. 26, da lei penal: imputável é o indivíduo que era, ao tempo da ação, inteiramente capaz de entender a ilicitude de sua prática e de determinar-se de acordo com esse entendimento. Mas em que consiste essa capacidade? 
É a "capacidade psíquica de motivação pela norma jurídica" (OLIVÉ et al., 2011, p. 462). Entende-se que como não seria empiricamente viável conceituar imputabilidade apenas como capacidade psíquica, uma vez que implicaria em fundamentá-la exclusivamente no livrearbítrio, seu conceito teve de ser reelaborado para comportar também um significado objetivo. Daí porque falar em "motivação pela norma jurídica". É o texto legal que constrói, delimita e aplica a capacidade psíquica quando confrontada com o caso concreto.

Diz que a inimputabilidade é de caráter biopsicológico, pois, ao tempo da ação, devem coexistir a insanidade mental ou o desenvolvimento mental incompleto ou retardado (aspecto biológico), e a incapacidade de compreensão do caráter ilícito do ato ou de autodeterminação (aspecto psicológico), sem os quais não se pode falar em irresponsabilidade penal.

Dito isto, resta analisar a irresponsabilidade penal, último conceito normativo relacionado à medida de segurança. Neste ponto, reside uma incongruência jurídica.

De uma forma bem direta, responsabilização penal é a consequência jurídica de um crime. Se há tipicidade, antijuridicidade e culpabilidade, o Estado pode responsabilizar o agente e aplicar-lhe uma pena. Assim, para a doutrina majoritária, como a inimputabilidade denota ausência de culpabilidade, não há que se falar em crime, tampouco em responsabilidade penal, o que justificaria a imposição de medida de segurança, e não uma pena propriamente dita.

O problema reside no fato de que, apesar de esbravejarem que a medida de segurança não é pena, não deixa ela de ser uma consequência penal ao cometimento de um injusto. Se há uma consequência jurídica para o agente, há que se falar em responsabilização, do contrário, o Direito Penal não agiria. E pior, trata-se de uma responsabilidade sem culpa, objetiva (FUHRER, 2000, p. 82).

Existe, portanto, uma diferença de aplicação entre as dirimentes de culpabilidade. A coação irresistível, a obediência hierárquica, o erro de proibição inevitável e as descriminantes putativas efetivamente geram uma irresponsabilização penal, posto que não há qualquer consequência jurídica para o agente. Comprovadas durante o processo, implicam em absolvição. Com a inimputabilidade por doença mental é diferente, a absolvição é dita imprópria e o agente é submetido a uma restrição de liberdade, ainda que sob o véu do tratamento médico. 
Daí perguntar-se: "se não praticou, a rigor, crime, por que cuidar do portador de sofrimento mental infrator o direito penal?" (MATTOS, 2006, p. 103). Voltamos à questão da presunção de periculosidade...

A medida de segurança surge dentro do panorama exposto no primeiro capítulo, referente ao embate entre a escola liberal e a escola positivista. Como o segundo entendimento desembocava, invariavelmente, na imposição de pena a qualquer indivíduo que representasse uma ameaça à defesa social e, deste modo, abalava toda a estruturação do direito penal clássico, surgiu uma espécie de meio termo entre esses dois posicionamentos (JACOBINA, 2008, pp. 129 - 130).

O meio termo representaria, assim, a duplicidade da reposta penal frente ao crime: a pena e a medida de segurança. A primeira surge da constatação da culpabilidade, a segunda da periculosidade. Para Weigert (2017, p. 75):

O sistema de medidas (de segurança) tem como conceito-chave a periculosidade, liga-se, pois, ao paradigma etiológico, punindo não porque a pessoa possui livre- arbítrio e age contrariamente ao direito, mas porque o sujeito não tem capacidade de autodeterminar-se, já que é doente/perigosa. Claro fica, portanto, que a medida de segurança acaba por castigar o agente pelo que ele é (perigoso) e não efetivamente pelo ato praticado.

A existência de duas respostas penais distintas ao crime é própria do sistema dualista, em contraposição ao monismo. Este último elege apenas um instrumento de intervenção criminal para o infrator. Cunhado por Von Liszt, no fim do século XIX, o monismo não diferencia medida de segurança de pena, posto que ambas devem ter como princípio norteadora prevenção de delitos. O objetivo, portanto, é inocuizar toda e qualquer ação criminosa, jáque ela representa a exteriorização das condições deletérias do próprio indivíduo (OLIVÉ et al., 2011, p. 684-685).

Felizmente (ou não), o dualismo distingue os dois institutos, atribuindo-lhes objetivos específicos, ainda que com um fundamento em comum: a contenção. Dentro do sistema dualista há duas vertentes: a sucessiva e a alternativa. Na alternativa, ou se aplica pena (imputáveis e semi-imputáveis), ou se aplica medida de segurança (inimputáveis e semi- imputáveis). Não há espaço para a imposição de duas consequências penais a um mesmo fato. Essa última hipótese, logicamente, é a defendida pelo dualismo sucessivo, também chamado de duplo-binário, onde o agente perigoso - a exemplo do criminoso habitual - cumpre pena por tempo determinado e, ao final desta, é imposta a ele uma medida de segurança por período incerto, a fim de contê-lo e curá-lo (OLIVÉ et al., 2011, p. 686 - 687). 
No Brasil, o sistema do duplo-binário foi o adotado pelo Código Penal de 1940, o mesmo que concretizou o instituto da medida de segurança no ordenamento pátrio - não por acaso, sob o regime totalitário do Estado Novo. Com a Reforma de 1984, esse entendimento foi alterado. Não mais subsiste a aplicação simultânea de pena e medida de segurança para o imputável e semi-imputável. Para este último, há apenas a possibilidade de substituição de um instituto pelo outro, de acordo com a análise do caso concreto.

Após analisarmos o surgimento da medida de segurança e seu papel no sistema penal, impõe-se uma breve análise acerca de sua previsão e aplicação pela legislação penal brasileira. Primeiramente, deve-se ressaltar que a imposição dessa medida está condicionada à existência de três pressupostos, sem os quais não há que se falar em absolvição imprópria, são eles: prática de um injusto penal, periculosidade do agente e ausência de imputabilidade plena (BITENCOURT, 2016, p. 864-865). Todos eles, em algum momento deste trabalho, foram analisados.

Da leitura do art. 96, do CP infere-se que são duas as espécies de medida desegurança: detentiva e restritiva. A primeira, segundo previsão de seu art. 97, caput, é imposta para os crimes apenados com reclusão, e importa em internação no HCTP. A segunda, para aqueles apenados com detenção, e pode implicar em submissão a tratamento ambulatorial.

Há de se notar que a imposição de tratamento ambulatorial não significa a impossibilidade de posterior medida detentiva, pois o art. 97, §4 $4^{\circ}$, do CP prevê que "em qualquer fase do tratamento ambulatorial, poderá o juiz determinar a internação do agente, se essa providência for necessária para fins curativos".

Apesar de o art. 99, do CP prever que o HCTP será um estabelecimento dotado de características hospitalares, com a finalidade de tratamento de seus internados, não há como negar suas características prisionais, mormente pelo fato de pertencer ao sistema criminal de justiça e promover a privação de liberdade do indivíduo, coercitivamente.

A legislação penal, lamentavelmente, determina que a internação - e também o tratamento ambulatorial - terão prazo máximo indeterminado, dependentes do exame de cessação de periculosidade, o qual será realizado após o transcurso do prazo mínimo estabelecido (1 a 3 anos) e, depois, anualmente. É o que preconiza os $\S \S 1^{\circ}$ e $2^{\circ}$, do art. 97 , do CP. Há neste ponto três questões que precisam ser destrinchadas.

Primeiramente, a partir daí, há uma transformação da presunção absoluta de periculosidade para relativa, uma vez que a internação, agora, dependerá de efetiva prova 
pericial de existência de perigo, diferentemente do momento de imposição da medida, quando basta a constatação do injusto e da situação de inimputabilidade (FUHRER, 2000, p. 149).

Outro ponto é a previsão de um prazo mínimo para o cumprimento da medida, o que revela, ao mesmo tempo, uma incongruência com o pretenso caráter "terapêutico" da periculosidade do indivíduo, já que poderia haver a cessação desse "mal" antes do decurso desse prazo, mas, mesmo assim, a medida deveria terminar de ser cumprida. Fato este que denota, segundo Weigert (2017, p. 100), “a adoção subliminar de um sentido retributivo da sanção aos doentes mentais que praticam fatos previstos como crimes".

Por fim, e a mais problemática, é a inexistência de prazo máximo para a duração da medida de segurança. Uma internação no HCTP pode, facilmente, transformar-se em uma segregação perpétua. Apesar de, como já dito, não ser a medida de segurança pena em si, ela é sanção penal e possui inegável caráter aflitivo. Daí afirmar-se que a vedação constitucional da aplicação de pena de caráter perpétuo é plenamente aplicável a esse instituto.

Da tentativa de estabelecimento de prazo máximo para a duração da medida de segurança, originaram-se duas vertentes: a que estabelece prazo não superior a 30 (trinta) anos, independentemente do tipo de crime, e a de prazo correspondente à pena máxima abstratamente cominada ao delito (BITENCOURT, 2016, p. 868-869). A primeira tem por base o prazo máximo de cumprimento de uma pena privativa de liberdade no Brasil, consubstanciado no art. 75, caput, do CP. Neste sentido, os precedentes do STF: HC 107.432/RS e HC 97.621/RS. Já a segunda é entendimento mais recente do STJ que, diante de jurisprudência pacificada, editou a súmula $\mathrm{n}^{\circ}$ 527, em 2015, a qual preleciona: “o tempo de duração da medida de segurança não deve ultrapassar o limite máximo da pena abstratamente cominada ao delito praticado".

\section{A REFORMA PSIQUIÁTRICA E O HOSPITAL DE CUSTÓDIA E TRATAMENTO PSIQUIÁTRICO}

A escolha por contextualizar o movimento global da Reforma Psiquiátrica a partir da segunda metade do século XX é decorrência do fato de que esse panorama teve importante repercussão na política psiquiátrica brasileira, ao reorientar o modelo de gestão em saúde mental a partir da Lei de n. 10.216/2001. Assim, para analisar a referida legislação, é preciso compreender o movimento que a originou.

Do que já foi dito sobre o surgimento do $\mathrm{MJ}$, pode-se concluir que o entendimento 
dado à loucura e a escolha de seu tratamento, em cada momento histórico, influenciam, ao menos teoricamente, a percepção do louco-infrator e a forma de lidar com ele.

A Reforma Psiquiátrica é decorrência de uma mudança na percepção, e consequente tratamento, do sofrimento mental, a qual possui raízes desde o surgimento da especialidade médica. Dentre as inúmeras vertentes desse movimento de renovação, as que aqui serão abordadas correspondem a um percurso teórico, mais ou menos cronológico, que irá desembocar no efeito prático de superação do modelo clássico de Psiquiatria.

“O modelo clássico restringe o espaço de atenção à saúde à sua natureza biológica ou organicista $[\ldots]$ centra as estratégias terapêuticas no indivíduo, extraído do contexto familiar e social" (COSTA, 2016, p. 11). Também chamado de modelo tradicional, nunca esteve isento de críticas, contudo, elege-se determinado momento histórico como sendo aquele que, a nível global, efetivamente lançou as bases teóricas para a sua futura superação. Está-se a falar do pós Segunda Guerra Mundial, o qual correspondeu a um período de "crescimento econômico e reconstrução social, de grande desenvolvimento dos movimentos civis e de maior tolerância e sensibilidade para com as diferenças e minorias” (DESVIAT, 2015, p. 27). Era um panorama propício para que as comunidades voltassem os olhos para as violências, físicas e emocionais, perpetradas dentro dos Manicômios, os quais faziam nada mais do que cronicizar seus pacientes.

Neste aspecto, é importante ter em mente que Reforma Psiquiátrica não é sinônimo de desospitalização, apesar de esta última ser uma de suas características. Há movimentos reformadores, por exemplo, que não visam a superação do Manicômio enquanto local de tratamento da loucura, mas apenas a sua reformulação interna, como é o caso da psicoterapia institucional, na França, e a comunidade terapêutica, na Inglaterra.

É comum dividir o tema dos movimentos, em termos globais, em três importantes períodos. Segundo Amarante (2016, p. 22), o primeiro é marcado por críticas à estrutura asilar, mas sem dispensar o manicômio enquanto espaço propício de cura, pois uma reforma interna seria suficiente. Já o segundo período caracterizou-se pela expansão da Psiquiatria à comunidade, na promoção da saúde mental. Para o autor, estes dois momentos restringiram-sea reformas do modelo psiquiátrico que em nada afetaram a existência da instituição manicomial. Diferentemente, o terceiro momento, representado pela antipsiquiatria e pelo pensamento basagliano, promoveu uma verdadeira ruptura na constituição do saber e prática psiquiátricos, pois rejeitaram a tradição de objetificação, aprisionamento de conceitos e redução de 
complexidade de fatos, ao atuar num campo mais profundo: o da epistemologia.

É importante dar enfoque à Psiquiatria Basagliana, tamanha a sua reverberação no movimento reformador brasileiro, especialmente na aprovação da Lei 10.216/2001.

Franco Basaglia, psiquiatra italiano, ainda na década de 60, quando era diretor de um Manicômio na pequena cidade italiana de Gorizia e influenciado pela psiquiatria inglesa, implantou o sistema de comunidade terapêutica naquele hospital (AMARANTE, 2016, p. 47). Contudo, apesar de utilizar esse mecanismo para gerar uma crise institucional dentro do hospital, de forma a projetar a psiquiatria também para o extramuros, entendia-o como insuficiente para responder às suas indagações acerca da própria relação de tutela que a Psiquiatria mantém com o doente mental.

Após sua experiência em Gorizia, quando começou a repensar o modelo psiquiátrico então vigente, Basaglia passa a atuar em um manicômio na cidade italiana de Trieste, na década de 70, e agora, convicto da insuficiência da comunidade terapêutica, cria um novo modelo de Psiquiatria, denominada de anti-institucional (AMARANTE, 2016, p. 49). Não vaise limitar à desospitalização, e consequente extinção dos manicômios, mas à criação de toda uma rede de tratamento da doença mental, com características variáveis, buscando manter sempre a vivência social do indivíduo, sem a sua anulação.

As mudanças ocorridas no ambiente regido por Basaglia correspondiam à: desmontagem do aparato manicomial, construção de centros de saúde mental, criação de residências comunitárias para egressos e cooperativas de trabalho (AMARANTE, 2016, p. 4950). Observa-se que a tradição basagliana extrapola a área médica e parte para uma redefinição sócio-política do louco, a partir da retomada de sua cidadania e da sua subjetividade, dentro da própria comunidade.

A Reforma Psiquiátrica no Brasil, a exemplo do que ocorreu no restante do mundo, também caminhou para a superação do modelo clássico da Psiquiatria, o qual não mais se adequava à nova percepção médico-social da loucura. Ela está inserida, juntamente com o resto da América Latina, em uma conjuntura política de desassistência à saúde mental, que fez surgir movimentos civis reivindicatórios de mudanças nessa área, a partir da década de 70 (DESVIAT, 2015, p. 136-137).

Especificamente no Brasil, a conjuntura era a dos últimos anos do período ditatorial, época em que a sociedade passa a "problematizar a estrutura e a organização do poder, as políticas sociais e econômicas, e também as condições cotidianas de vida e trabalho" 
(AMARANTE, 2016, p. 89). Tal fato enseja a organização de movimentos civis que clamam por mudanças políticas em diversos setores, a partir de uma redemocratização do espaço público, estando aí incluído o da saúde mental.

O movimento brasileiro pode ser dividido em três fases: a alternativa, a sanitarista e a desinstitucionalizante (AMARANTE, 2016, p. 89-96). A primeira, que coincide com o período que antecede a redemocratização, vê o surgimento de um número significativo de movimentos civis, a exemplo do Movimento de Trabalhadores em Saúde Mental (MTSM), responsável por inúmeras denúncias de violação aos direitos humanos dentro dos Manicômios, bem como da corrupção administrativa perpetuada nesses ambientes, a qual denotava um completo descaso do Estado para com a saúde mental de sua população (AMARANTE, 2016, p. 89-90). As reinvindicações desse grupo restringiam-se à busca de um modelo alternativo de tratamento do louco, a partir de mudanças de cunho humanitário dentro da própria instituição asilar.

Já na década de 80, essas críticas ensejarão o clamor público pela reestruturação do sistema nacional de saúde, com a proposta de implementação de programas alternativos e da universalidade de acesso ao tratamento psiquiátrico, em grande parte como resposta à privatização desenfreada que esse setor vinha sofrendo (TENÓRIO, 2002, p. 32-34). Apesar de as denúncias de maus tratos e corrupção, relatadas na fase anterior, terem tido algum efeito sobre a estruturação dos Hospitais Psiquiátricos no Brasil, os quais passaram a ser fiscalizados com mais acuidade, permaneciam os problemas relativos à desassistência social em massa da população.

Trata-se da fase sanitarista, a qual corresponde à incorporação dos movimentos reformistas pelo aparelho estatal, inclusive com a nomeação de algumas de suas lideranças para cargos governamentais. De certa forma, caracteriza-se por ser um período institucionalizante, que abre mão de questionamentos a respeito do próprio papel da Psiquiatria (AMARANTE, 2016, p. 91).

Fora desse ambiente atenuador da problemática Psiquiatria asilar, os movimentos civis continuavam a reivindicar mudanças mais profundas no setor. Realizavam-se encontros e conferências nacionais, regionais e municipais que agregavam diversos segmentos sociais para a discussão do problema (AMARANTE, 2016, p. 92). Nesse panorama, o MTSM realiza a I Conferência Nacional de Saúde Mental (CNSM), em 1987, um marco para a Reforma Psiquiátrica brasileira, pois delimita "o início da trajetória de desconstruir no cotidiano das 
instituições e da sociedade as formas arraigadas de lidar com a loucura. É a chamada desinstitucionalização" (TENÓRIO, 2002, p. 35).

Neste momento, os atores políticos organizam-se num movimento nacional de luta antimanicomial que finalmente cria propostas alternativas ao ambiente asilar, tendo sempre por pressuposto o resgate da cidadania do doente mental, em uma nítida influência do movimento basagliano (CORREIA, 2007, p. 105-106). Assim, a fase desinstitucionalizante está inserida num panorama de estruturação de práticas substitutivas às hospitalares, a exemplo dos Centros de Atenção Psicossocial (CAPS) e dos Núcleos de Atenção Psicossocial(NAPS).

Nesse contexto de luta antimanicomial, ergue-se, também, um movimento legislativode consolidação da Reforma, a partir da apresentação, em 1989, do Projeto de Lei $n^{\circ} 3.657$, do então deputado federal Paulo Delgado (TENÓRIO, 2002, p. 34-36). Tal projeto visava a reformulação da assistência psiquiátrica no Brasil, consubstanciada na progressiva extinção dos manicômios e no disciplinamento da internação compulsória. Elaborado com apenas três artigos previa, resumidamente, a proibição de construção de novos hospitais psiquiátricos no país, o fortalecimento dos serviços extrahospitalares pela administração pública e a obrigação de comunicação à autoridade judiciária, dentro de 24 horas, acerca das internações compulsórias. Seu fruto é a Lei 10.216/2001, também chamada de Lei da Reforma Psiquiátrica,

É bem verdade que a Lei aprovada deixa a desejar, quando comparada ao seu projeto inicial, em relação à ausência de previsão explícita acerca da progressiva extinção dos Hospitais Psiquiátricos no país e da definição de responsabilidades pela estruturação das terapias alternativas, muito pelo fato de que teve oposição ferrenha de setores conservadores em seu trâmite legislativo, a exemplo dos empresários do ramo. Contudo, mesmo que esses dois pontos não tenham sido diretamente tratados pela legislação, dela podem ser extraídas diretrizes que possuem efeito prático semelhante (TENÓRIO, 2002, p. 52-53).

Assim, alguns artigos da Lei podem ser elegidos como sendo aqueles que melhor transparecem os objetivos desospitalizantes e desinstitucionalizantes da Reforma Psiquiátrica. Outrossim, eles também são aqueles que melhor constroem uma ponte entre a norma e a questão do louco-infrator, uma vez que a assimilação dessas diretrizes influencia a própria estruturação asilar do HTCP.

$\mathrm{O}$ art. $1^{\circ}$ é de extrema importância para a análise da possível influência dessediploma legal na questão do portador de transtorno mental autor de delitos. Conforme depreende-se da sua leitura, as previsões protetivas constantes em seu corpo textual aplicam- se a todos os 
doentes mentais, estejam eles ligados ao sistema de justiça criminal ou não, posto que é vedado qualquer tipo de discriminação (CORREIA, 2007, p. 112). Assim, as disposições penais relativas à aplicação e execução da medida de segurança, em especial a do tipo detentiva, devem estar em consonância com as diretrizes elencadas pela norma.

Merece destaque, também, o parágrafo único de seu art. $2^{\circ}$, o qual elenca um rol de direitos assegurados aos portadores de transtornos mentais que devem ser respeitados, especialmente quando do atendimento, de qualquer natureza, em saúde mental. Dos 9 incisos constantes no citado artigo, dois claramente demonstram a influência da Reforma Psiquiátrica no planejamento da assistência médica ao doente mental, são eles os incisos II e IX. O inciso II reforça a necessidade de que, qualquer que seja o tratamento dispensado ao portador de transtorno mental, ele deve objetivar sempre a inserção do indivíduo na sociedade, em suas mais variadas vertentes. Assim, a princípio, o tratamento não deve ser a internação, posto que segregativa, e sim a aplicação de práticas comunitárias, a exemplo de oficinas e residências terapêuticas. Entendimento reforçado pelo que dispõe o inciso IX: "ser tratada, preferencialmente, em serviços comunitários de saúde mental".

Contudo, é importante ter em mente que a Lei 10.216/2001 não exclui a hipótese deo indivíduo ser internado, e tal previsão já pode ser observada a partir do seu art. $4^{\circ}$. O que se deve destacar, entretanto, é o cuidado do legislador ao prever que tal medida apenas pode ser imposta quando "os recursos extra - hospitalares se mostrarem insuficientes". Outrossim, a internação não pode ocorrer em instituições com características asilares, ou seja, naquelas que não visem a reinserção social do paciente, que não possuam assistência integral, que não estejam em consonância com o regime protetivo do art. $2^{\circ}$ e que não respeitem a vedação ao asilo prolongado prevista no art. $5^{\circ}$.

Mesmo que a análise dos artigos acima mencionados facilmente conclua pela aplicação de suas disposições aos casos dos portadores de transtornos mentais em conflitocom a lei, na prática isso não gera tanta certeza ao Poder Judiciário, o qual segue aplicando as normativas clássicas. Como afirma Weigert (2017, p. 105), “a lei e qualquer movimento alternativo à psiquiatria convencional parecem simplesmente não tocar o universo dos loucos que são considerados infratores".

\section{CONCLUSÃO}

Para falar sobre o surgimento do HCTP, uma instituição híbrida, foi necessário 
construir o percurso de interlocução entre a Psiquiatria e o Direito Penal na criação de um indivíduo ao mesmo tempo louco e criminoso, além de perigoso. Como dito, a Psiquiatria surge, em fins do século XVIII, da transformação da loucura em seu objeto de atuação científica, a qual não se restringe apenas à produção teórica sobre fenômenos mentais e comportamentais, mas também à produção de mecanismos de intervenção sobre esses fenômenos, a exemplo dos manicômios.

A interlocução desse novo saber-poder com o Direito Penal ocorreu quando osjuristas requisitaram dos psiquiatras que examinassem indivíduos que haviam cometidos crimes brutais, e que, por isso mesmo, geravam desconfiança quanto à sua sanidade mental. Ao tentar explicá-los, a Psiquiatria criava cada vez mais teorias que, ao invés de inseriremseus crimes enquanto episódios da sua loucura, como usualmente fazia, identificavam a própria criminalidade como espécie de insanidade mental. E mais, à essa nova categoria nosológica, o louco-criminoso, não mais poderia ser aplicado o binômio clássico doença-cura, o qual foi substituído pela periculosidade-contenção.

Aí está precisamente o ponto de encontro, e choque, entre os saberes médico e jurídico. Se este tipo de criminalidade correspondia a um estado mórbido, o Direito Penal não poderia exercer seu jus puniendi, já que fundado no livre-arbítrio. Por outro lado, se essa criminalidade era um estado médico, mas incurável, a Psiquiatria não poderia utilizar seus mecanismos clássicos de tratamento.

A convergência surge na atribuição simultânea por esses saberes de periculosidade ao louco-criminoso, justificativa suficiente para a sua contenção, em nome da defesa social. E como o manicômio comum não poderia recebê-lo, pois sua categoria nosológica não se enquadrava em seu plano terapêutico, e como a prisão não era possibilidade por conta de sua inimputabilidade, uma nova instituição surgiu para segregá-lo: o MJ.

Com isso, a permanência do MJ ao longo dos séculos XX e XXI não requereu muito esforço por parte dessas instâncias, ainda que a ideia de identificação da criminalidade como distúrbio psiquiátrico tenha perdido força. A construção da periculosidade presumida doloucoinfrator basta para que o HCTP se sustente. Quem ousa pensar que ele não precisaria ser contido?

Ocorre que, na contramão dessa prática segregacional, a denominada Reforma Psiquiátrica, regulada no Brasil pela Lei 10.2016/2001, reinterpretou o portador de transtorno mental, bem como reformulou seu tratamento psiquiátrico para inseri-lo na comunidade e 
resgatar sua cidadania. Em meio às práticas desinstitucionalizantes, uma delas tornou-se marcante: a extinção dos manicômios. E a questão que surge é a de que, dentro desse novo panorama teórico, onde o perigo não é intrínseco à loucura, mas à sua incompreensão, e onde a segregação manicomial não é admitida, há espaço para o HCTP?

\section{REFERÊNCIAS}

AMARANTE, Paulo (Coord). (1995). Loucos pela vida: a trajetória da Reforma Psiquiátrica no Brasil. 2. ed. Rio de Janeiro: Fiocruz, 2016.

BITENCOURT, Cezar Roberto. Tratado de Direito Penal: parte geral. 22. ed. São Paulo: Saraiva, 2016. 5 v.

CARRARA, Sérgio. Crime e Loucura: o aparecimento do manicômio judiciário na passagem do século. Rio de Janeiro: EdUERJ; São Paulo: EdUSP, 1998.

CORREIA, Ludmila Cerqueira. Avanços e impasses na garantia dos direitos humanos de pessoas com transtornos mentais autoras de delito, 2007. $174 \mathrm{f}$. Dissertação (Mestrado em Direito). Programa de Pós-Graduação em Ciências Jurídicas, Universidade Federal da Paraíba, Paraíba. Disponível em: https://repositorio.ufpb.br/jspui/handle/123456789/16008?locale=pt_BR. Acesso em: 17 jul. 2021.

COSTA, Nilson do Rosário. Prefácio. In: AMARANTE, Paulo (coord.). Loucos pela vida: a trajetória da Reforma Psiquiátrica no Brasil. 2 ed. Rio de Janeiro: Fiocruz, 2016.

DESVIAT, Manuel. (1999). A reforma psiquiátrica. 2. ed. Rio de janeiro: Fiocruz, 2015. FOUCAULT, Michel. (1973). A verdade e as formas jurídicas. Rio de Janeiro: Nau, 2013

FOUCAULT, MICHEL. (1974-1975). Os anormais: curso no Collège de France (19741975). 2. ed. SãoPaulo: WMF Martins Fontes, 2010.

FÜHRER, Maximiliano Roberto Ernesto. Tratado da inimputabilidade no Direito Penal. SãoPaulo: Malheiros Editores, 2000.

GOFFMAN, Erving. (1961). Manicômios, prisões e conventos. São Paulo: Perspectiva, 2015.

HARRIS, Ruth. Assassinato e loucura: Medicina, leis e sociedade no fin de siècle. Rio de janeiro: Rocco, 1993.

JACOBINA, Paulo Vasconcelos. Direito Penal da Loucura: Medida de segurança e reforma psiquiátrica. Brasília: ESMPU, 2008. Disponível em: https://escola.mpu.mp.br/publicacoes/obras-avulsas/e-books/direito-penal-da loucura/@@download/arquivo/Direito\%20Penal\%20da\%20Loucura.pdf. Acesso em: 17 jul. 2021.

MATTOS, Virgílio. Crime e psiquiatria: uma saída: preliminares para a desconstrução das 
medidas de segurança. Rio de Janeiro: Revan, 2006.

OLIVÉ, Juan Carlos Ferré et al. Direito penal brasileiro: parte geral: princípios fundamentais e sistema. São Paulo: Revista dos Tribunais, 2011.

TENÓRIO, Fernando. A reforma psiquiátrica brasileira, da década de 1980 aos dias atuais: história e conceitos. In: História, Ciências, Saúde - Manguinhos, Rio de Janeiro, v. 9, n. 1, pp. 25-59, jan. - abr. 2002. Disponível em: 〈http://www.scielo.br/pdf/hcsm/v9n1/a03v9n1.pdf>. Acesso em: 17 jul. 2021.

WEIGERT, Mariana de Assis Brasil e. Medidas de segurança e reforma psiquiátrica: silêncios e invisibilidades nos manicômios judiciários brasileiros. Florianópolis: Empório do Direito, 2017. 